J. Lake Sci. (湖泊科学) , 2011, 23(3): 375-382

http: //www. jlakes. org. E-mail : jlakes@niglas.ac.cn

(c) 2011 by Journal of Lake Sciences

\title{
三峡水库香溪河库湾春季水华期间浮游植物昼夜垂直分布与迁移”
}

\author{
杨 敏 ${ }^{1,2,3}$, 毕永红 ${ }^{1}$, 胡建林 ${ }^{1}$, 胡征宇 ${ }^{1 * *}$ \\ ( 1 : 中国科学院水生生物研究所淡水生态与生物技术国家重点实验室,武汉 430072) \\ (2: 中国科学院研究生院,北京 100049) \\ ( 3 : 重庆市环境科学研究院,重庆 401147)
}

摘 要: 三峡水库蓄水后,香溪河库湾每年春季均会暴发硅、甲藻水华. 为了揭示香溪河库湾水华的暴发规律,于 2008 年 春季对水华期间优势浮游植物的昼夜垂直分布格局及其影响因子进行了研究. 利用时间深度等值图模拟浮游植物在水 柱中的昼夜垂直分布格局, 并用 Morisita 指数对其进行定量检验, 采用修正的 K-S test 来检验浮游植物是否存在昼夜垂直 迁移现象. 结果表明,在甲藻水华发生的吴家湾样点,倪氏拟多甲藻 (Peridiniopsis niei)、膝曲裸藻 (Euglena geniculata) 和具 尾逗隐藻 (Komma caudata) 为优势种类, 相对密度分别为 $53.47 \% 、 14.36 \% 、 21.94 \%$. 倪氏拟多甲藻具有明显的昼夜垂直 迁移现象,白天主要聚集分布于水体近表层, 晚间在水柱中趋于均匀分布; 膝曲裸藻和具尾逗隐藻没有明显的昼夜垂直 迁移活动, 它们主要聚集分布于水体亚表层, 但随着白天光照强度的增强均表现出一定的趋光性. 在硅藻水华发生的平 邑口样点, 优势种类为汉斯冠盘藻 (Stephanodiscus hantzschii) 和塔胞藻 (Phramidomonas sp. ) (相对密度分别为 89.53\% 和 $7.96 \%$ ). 汉斯冠盘藻昼夜垂直分布类型无显著差异, 主要聚集分布于 $4 \mathrm{~m}$ 以上水体; 塔胞藻具有昼夜垂直迁移现象. Sperman 相关分析表明, 光照强度的变化是引起倪氏拟多甲藻和塔胞藻昼夜垂直迁移行为的主要环境因素, 而其他藻类 的昼夜垂直分布格局与光照强度的变化无显著相关. 膝曲裸藻和具尾逗隐藻的昼夜垂直分布格局可能受光照的变化及 水体扰动的共同影响. 汉斯冠盘藻不能自由游动,其昼夜分布格局可能主要受水体扰动的影响.

关键词: 浮游植物;垂直分布; 迁移;春季水华;香溪河库湾;三峡水库

\section{Diel vertical migration and distribution of phytoplankton during spring blooms in Xiangxi Bay, Three Gorges Reservoir}

\author{
YANG Min $^{1,2,3}$, BI Yonghong ${ }^{1}$, HU Jianlin ${ }^{1} \&$ HU Zhengyu ${ }^{1}$ \\ (1: State Key Laboratory of Freshwater Ecology and Biotechnology, Institute of Hydrobiology, Chinese Academy of Sciences, \\ Wuhan 430072 , P. R. China) \\ (2: Graduate School of Chinese Academy of Sciences, Beijing 100049, P. R. China) \\ (3: Chongqing Academy of Environmental Sciences, Chongqing 401147, P. R. China)
}

Abstract: Diatoms and dinoflagellate blooms have always occurred in spring in Xiangxi Bay since the impoundment of Three Gorges Reservoir. Vertical distribution and migration of dominant phytoplankton were studied during two diel periods in Xiangxi Bay in spring 2008, which may be fundamental to understand the outbreak of bloom. In the present study, Peridiniopsis niei, Euglena geniculata and Komma caudata dominated in WJW, accounted for 53.47\%, $14.36 \%$ and $21.94 \%$ of total abundance, respectively. While in PYK, Stephanodiscus hantzschii and Phramidomonas sp. were dominant, and the relative abundance was $89.53 \%$ and $7.96 \%$, respectively. Mapping method was used to describe the time-depth distribution of phytoplankton individuals. The dispersion patterns for phytoplankton population were tested with Morisita index, and a modified two sample Komogorov-Smirnov was used to test differences in vertical distribution. Both $P$. niei and $P h$. sp. aggregated in the water upper layer in daytime and was close to a random distribution at night, performing diel vertical migration(DVM). E. geniculata and $K$. caudata did not display

* 国家重点基础研究发展计划项目(2008CB418002) 和国家水体污染控制与治理科技重大专项项目(2009ZX07104005 ) 联合资助. 2010-10-12 收稿;2010-11-23 收修改稿. 杨敏, 女, 1980 年生; E-mail: freefish19992003@yahoo. com. cn.

** 通讯作者; E-mail: huzy@ihb. ac. cn. 
DVM. They accumulated in upper water layers and showed phototaxis. S. hantzschii inhabited the upper water layer. There was no significant difference in day and night distribution. Sperman correlation analysis revealed that the diel vertical distribution of both $P$. niei and $P h$. sp. significantly correlated with light availability, but the other algae didn't. The vertical distribution pattern of $E$. geniculata and $K$. caudata may be influenced by dynamic of light availability and water column disturbance caused by wind. The vertical distribution of $S$. hantzschii which was non-motile may mainly affected by water column disturbance.

Keywords: Phytoplankton; vertical distribution; migration; spring bloom; Xiangxi Bay; Three Gorges Reservoir

在海洋和淡水水体中, 浮游植物在水柱中的垂直分布及昼夜垂直迁移 (Diel Vertical Migration, DVM) 受 到广泛关注 ${ }^{[1]}$, 研究的门类主要集中于鞭毛藻类 (甲藻、隐藻、衣藻类等) 和蓝藻 ${ }^{[2-5]}$, 对于一些不能自由游动 的硅藻、绿藻也有少量研究 ${ }^{[6]}$. 浮游植物的垂直迁移方式可以分为主动迁移和被动迁移两种. 一般来说, 细 胞密度比周围水体大的不能移动的种类属于被动迁移类型, 而大多数的真核鞭毛藻类或具有伪空泡的蓝藻 能够自主调节在水体中的位置, 属于主动迁移类型. 影响浮游植物昼夜分布与垂直迁移的环境因子包括光 照强度、水体分层、由风等所引起的水体扰动、浮游动物摄食压力、藻类个体大小等 ${ }^{[7-12]}$. 浮游植物昼夜垂直 分布和迁移在分层的湖泊和海湾中研究得比较多 ${ }^{[9,13-14]}$, 分层水体为水柱空间温度、营养盐、溶氧等理化因 子的异质性提供了条件.

三峡水库蓄水后, 香溪河下游河段水位随之升高, 水流减缓, 水环境由典型的河流水体转变为类似湖泊的 缓流水体, 富营养化程度加剧. 每年春季暴发的硅、甲藻水华 ${ }^{[15-16]}$, 持续时间长, 蔓延到整个库湾, 水面呈或深 或浅的酱油色, 严重影响了当地景观和生态系统服务功能. 目前关于三峡库区浮游植物的研究多见于季节演 替、水华发展过程等方面 ${ }^{[16-17]}$, 而对于昼夜垂直分布的研究仅限于甲藻 ${ }^{[18-20]}$, 尚未出现关于其他水华优势种如 硅藻、隐藻等昼夜垂直分布的研究. 春季水华过程中, 各优势浮游植物在水柱中如何分布? 是否具有昼夜垂直 迁移现象? 什么是浮游植物昼夜垂直迁移的主导因素? 基于以上问题, 我们对春季水华期间优势浮游植物的 昼夜垂直分布和迁移进行了研究, 以期揭示不同浮游植物的分布和迁移类型, 揭示香溪河库湾春季水华暴发 的规律, 确定影响垂直分布和迁移的主导因素, 为三峡库区水华监测和治理研究提供参考资料.

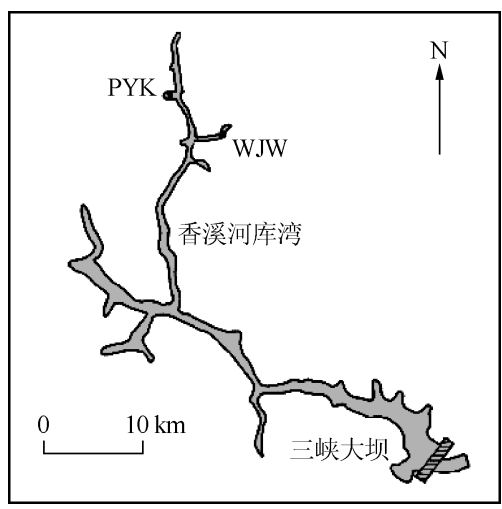

图 1 香溪河库湾采样点

Fig. 1 Location of sampling sites in Xiangxi Bay of Three Gorges Reservoir

\section{1 材料和方法}

\section{1 采样方法}

2008 年倪氏拟多甲藻水华发生期间, 在吴家湾采样点 (WJW: $31^{\circ} 7^{\prime} 4.19^{\prime \prime} \mathrm{N}, 110^{\circ} 47^{\prime} 59.43^{\prime \prime} \mathrm{E}$, 图 1) 进行 $24 \mathrm{~h}$ 昼夜分层 监测, 样点水深约为 $12 \mathrm{~m}$. 从 3 月 31 日 18:00 开始, 次日 16:00 结束, 每隔 $2 \mathrm{~h}$ 采样一次. 垂直水层设置为 $0.5 \mathrm{~m} 、 1 \mathrm{~m}$, 然后每隔 $1 \mathrm{~m}$ 设置一个采样层, 直至水深 $10 \mathrm{~m}$, 共计 11 个水层. 用 $5 \mathrm{~L}$ 采水器分 别在各个水层采集水样. 现场用水银温度计测量各水层水温, 用 ZDS $-10 \mathrm{~F}-2 \mathrm{D}$ 水下光量子仪测定光照强度.

取一份水样加 Lugol's 液固定后, 带回实验室沉淀浓缩, 用作浮 游植物的定量分析, 鉴定和分析方法参照文献 [21]. 另一份水样经 $0.45 \mu \mathrm{m}$ 微孔滤膜 (Whatman GF/F $47 \mathrm{~mm}$ 申) 过滤后, 锄酸铵分光光度 法测定 $\mathrm{PO}_{4}^{3-}-\mathrm{P}$, 分光光度法测定 $\mathrm{NO}_{3}^{-}-\mathrm{N}$; 叶绿素 a 经 WhatmanGF/F 膜过滤后用 $90 \%$ 丙酮提取, 然后用分光光度法测定 ${ }^{[22]}$.

2008 年 4 月, 在硅藻水华发生期间, 于平邑口采样点 ( PYK: $31^{\circ} 10^{\prime} \mathrm{N}, 110^{\circ} 45^{\prime} \mathrm{E}$, 图 1 ) 进行另一次昼夜分 层监测, 样点水深约 $9 \mathrm{~m}$. 从 4 月 29 日 10:00 开始, 次日 8:00 结束, 垂直水层设置、采样方法及所测量生物、 理化指标及分析处理方法同上.

\section{2 数据处理}

浮游植物细胞密度及叶绿素 $\mathrm{a}$ 的昼夜垂直分布格局采用时间深度等值图进行模拟, 时间深度等值图在 Surfer 软件 (Golden Software Surfer 8) 中绘制, 绘制过程中选用 Kriging 插值模拟. 同时, 选用 Morisita 指数 (Morisita Index, MI) 进一步定量检验浮游植物在水柱中的垂直分布格局 ${ }^{[23]}$ : 


$$
M I=n\left(\sum X_{i}^{2}-\sum X_{i}\right) /\left[\left(\sum X_{i}\right)^{2}-\sum X_{i}\right]
$$

式中, $n$ 为水柱取样的分层数, $X_{i}$ 为水柱中第 $i$ 层的浮游植物密度. 当 $M I=1$ 时, 表示浮游植物在水柱中随机 分布; 当 $M I<1$ 时, 表示浮游植物在水柱中均匀分布; 当 $M I>1$ 时, 表示浮游植物在水柱中集群分布 ${ }^{[24-25]}$.

为研究不同采样时间浮游植物群落是否存在昼夜垂直迁移现象, 采用修正过的 Kolmogorov-Smirnov $(\mathrm{K}-\mathrm{S})$ 检验, 该方法对一次采样数据所产生的离差不敏感 ${ }^{[26]}$, 而且适用于 DVM 研究 ${ }^{[27]}$.

以水下光强为水面光强 $1 \%$ 处的深度为真光层深度 ${ }^{[2]}$, 混合层深度的计算参照 Kunz 等的分法 ${ }^{[28]}$. 真光 层和混合层的比值 $Z_{\mathrm{eu}}: Z_{\mathrm{mix}}$ 计量光可见度 (Light Availability, $\left.L A\right)^{[29]}$. 将 $M I$ 指数与光可见度、水柱温差 (Water Column Temperature Difference, WCTD $)^{[23]}$ 进行 Sperman 相关分析, 用于检验光照、水温对浮游植物垂直分 布格局的影响. 相关分析在 SPSS 13.0 软件包中完成.

\section{2 结果}

\section{1 理化环境因子及垂直分布}

采样期间水表太阳光照强度昼夜差异显著, 清晨光强 最弱,之后逐渐升高,到中午或略过午后时到达最高,然后 光强降低,到晚上时光强为零 (图 2). 采样期间 WJW 样点 的水温范围为 $11.7-13.9^{\circ} \mathrm{C}$, 平均为 $12.8^{\circ} \mathrm{C} ; \mathrm{PYK}$ 样点的 水温范围为 $18.0-22.0^{\circ} \mathrm{C}$, 平均为 $20.0^{\circ} \mathrm{C}$; 两个样点各水层 间最大温度梯度没有超过 $1^{\circ} \mathrm{C} / \mathrm{m}$, 因此没有温跃层出现 ( 图 $3)$. WJW 样点的 $\mathrm{NO}_{3}^{-}-\mathrm{N}$ 浓度由表层向底层逐渐升高,范围 为 $0.549-0.899 \mathrm{mg} / \mathrm{L}$, 平均浓度为 $0.689 \mathrm{mg} / \mathrm{L} . \mathrm{PO}_{4}^{3-}-\mathrm{P}$ 浓度 从表层至水下 $6 \mathrm{~m}$ 逐渐升高, $8-10 \mathrm{~m}$ 略有降低,范围为 0 .

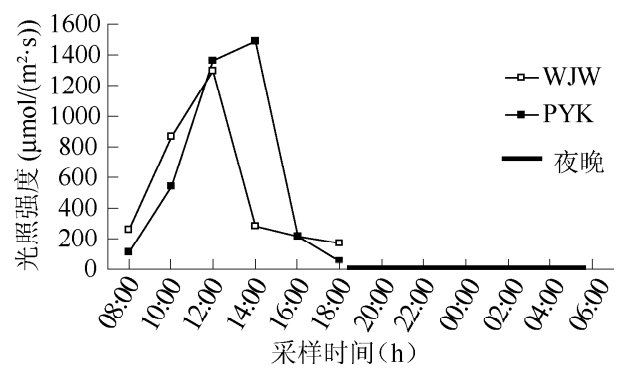

图 2 采样期间光照强度的变化

Fig. 2 Diel patterns of solar irradiance during sampling periods $0295-0.0395 \mathrm{mg} / \mathrm{L}$, 平均浓度为 $0.0335 \mathrm{mg} / \mathrm{L}$ (图 3a). $\mathrm{PYK}$ 样点 $\mathrm{NO}_{3}^{-}-\mathrm{N}$ 浓度由表层向底层逐渐升高, 范围为 $0.908-1.266 \mathrm{mg} / \mathrm{L}$, 平均浓度为 $1.103 \mathrm{mg} / \mathrm{L} . \mathrm{PO}_{4}^{3-}-\mathrm{P}$ 浓度从表层至底层逐渐升高, 范围为 $0.058-0.183 \mathrm{mg} / \mathrm{L}$, 平均浓度为 $0.131 \mathrm{mg} / \mathrm{L}$ (图 $3 \mathrm{~b}$ ).
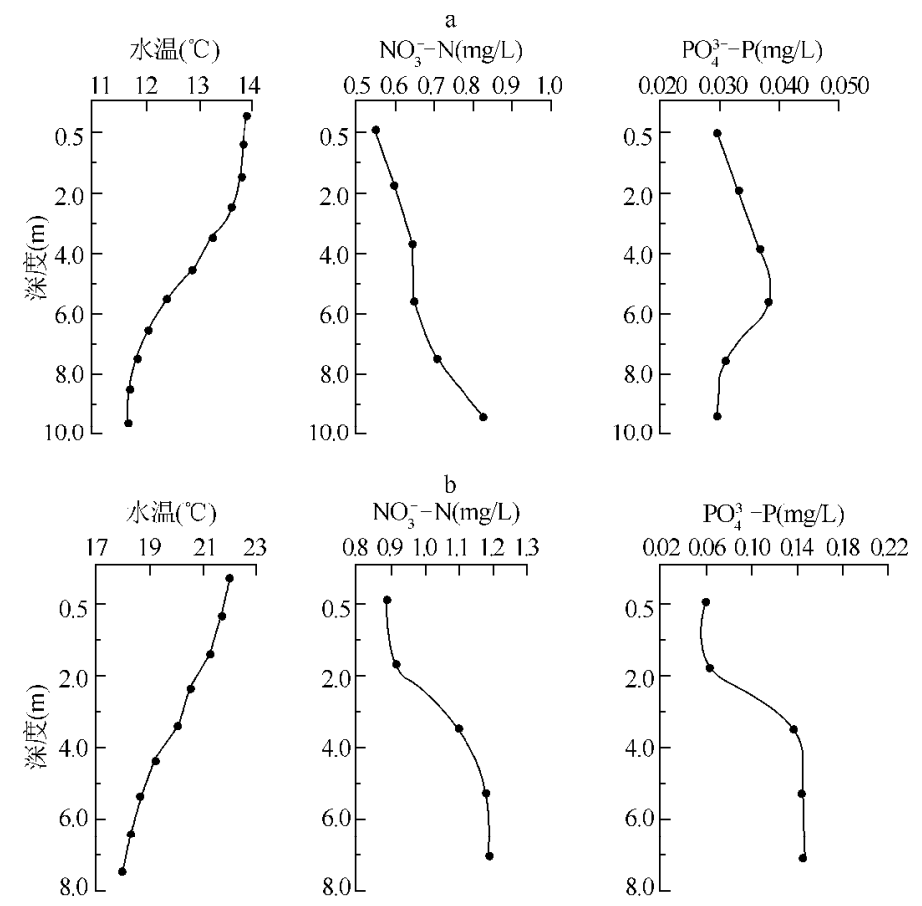

图 $3 \mathrm{WJW}(\mathrm{a})$ 和 $P Y K(b)$ 的水温和营养盐的垂直分布

Fig. 3 Vertical profiles of water temperature and nutrients in WJW(a) and PYK(b) 

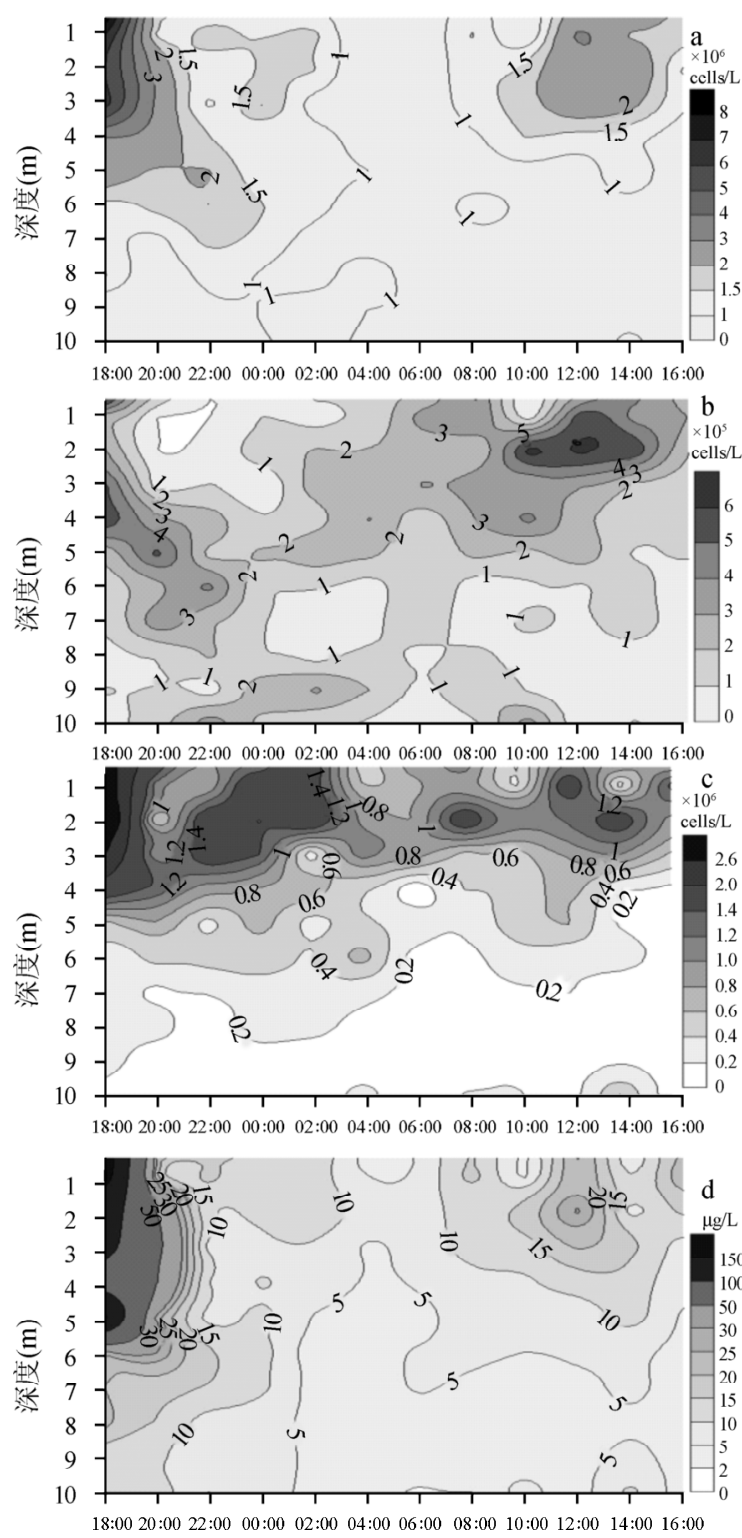

图 4 WJW 倪氏拟多甲藻 (a)、膝曲裸藻 (b)、 具尾逗隐藻 $(c)$ 和叶绿素 $a(d)$ 时间 深度等值图

Fig. 4 Depth-time diagram of Peridiniopsis niei( a), Euglena geniculata (b), Komma caudata (c) and Chl. a(d) in WJW

\section{2 叶绿素 a 垂直分布}

2.2.1 WJW 叶绿素 $\mathrm{a}$ 垂直分布 主要分布于 $6 \mathrm{~m}$ 以上水柱中, 最高密度出现在 18:00 时的 $0.5 \mathrm{~m}$ 水层, 为 $178.60 \mu \mathrm{g} / \mathrm{L}$ (图 $4 \mathrm{~d}$ ). $M I$ 指数表明, 晚 间 00:00 到 06:00, $M I$ 值小于 1, 叶绿素 a 在水 柱中均匀分布; 从 18:00 到 22:00 以及 08:00到 16:00, $M I$ 指数均大于 1 , 表明叶绿素 $\mathrm{a}$ 在水柱中 集群分布. 叶绿素 $\mathrm{a}$ 的昼夜垂直分布变化趋势与 倪氏拟多甲藻基本一致, 同时说明倪氏拟多甲 藻是第一优势种.

2.2.2 PYK 叶绿素a 垂直分布 主要分布在 $6 \mathrm{~m}$ 以上水柱中, 最高密度出现在 $16: 00$ 的 $0.5 \mathrm{~m}$ 水 层, 为 $91.12 \mu \mathrm{g} / \mathrm{L}$ (图 $5 \mathrm{c}$ ). $M I$ 指数为 $1.06-$ 1.54 , 表明叶绿素 a 在水柱中集群分布. 叶绿素 $\mathrm{a}$ 的昼夜垂直分布变化趋势与汉斯冠盘藻基本 一致, 同时说明汉斯冠盘藻是第一优势种.

\section{3 浮游植物垂直分布及昼夜迁移}

吴家湾采样点浮游植物的优势种有 3 种, 分别为倪氏拟多甲藻 (Peridiniopsis niei) 、具尾逗 隐藻 (Komma caudata) 和膝曲裸藻 (Euglena geniculata), 相对密度分别为 $53.47 \% 、 21.94 \%$ 、 $14.36 \%$; 平邑口采样点浮游植物优势种为汉斯 冠盘藻 (Stephanodiscus hantzschii) 和塔胞藻 (Phramidomonas sp.), 相对密度分别为 $89.53 \%$ 、 $7.96 \%$.

2.3.1 倪氏拟多甲藻 从 18:00 到 22:00, 倪氏 拟多甲藻在 $5 \mathrm{~m}$ 以上水柱中聚集分布, 最大密度 出现在 18:00 时的 $0.5 \mathrm{~m}$ 水层中 $(8.90 \times$ $10^{6}$ cells/L) ; 从 22: 00 开始到日出前, 倪氏拟多 甲藻在 $0.5 \mathrm{~m}$ 水层的密度均低于 $1 \mathrm{~m}$ 水层中的密 度, 在整个水柱中分布较均匀; 6: 00 日出后, $0.5 \mathrm{~m}$ 水层中的密度高于其他水层, 从 8:00 到 16:00, 集中分布于 $4 \mathrm{~m}$ 以上水体 (图 4a). $M I$ 值 的计算表明, 倪氏拟多甲藻白天在水柱中呈聚 集分布, $M I$ 指数在 1.10 到 1.65 之间; 在夜间趋 于随机分布, $M I$ 指数在 1.03 到 1.05 之间 (表 1). K-S 检验表明, 倪氏拟多甲藻具有明显的昼 夜垂直迁移现象 $(P<0.05)$.

2.3 .2 膝曲裸藻在 $10 \mathrm{~m}$ 水柱内均有分布, 最大 密度出现在 10:00 的 $2 \mathrm{~m}$ 水层, 为 $6.41 \times 10^{5}$

cells/L. MI 指数在 1.23-1.84(表 1), 表明在昼夜周期内聚集分布. 10: 00 至 14:00 之间, 随光照增强, 膝曲 裸藻向上水层迁移, 表现出一定的趋光性 (图 4b). K-S 检验表明膝曲裸藻在夜晚和白天的垂直分布类型没 有显著差异 $(P>0.05)$. 
表 1 优势浮游植物及水体叶绿素 a $M I$ 指数和水柱温差“

Tab. 1 MI of dominant phytoplankton, MI of Chl. a and WCTD

\begin{tabular}{cccccccccc}
\hline 时间 & MI-P. & MI-E. & MI-K. & MI-Chl. $a(\mathrm{WJW})$ & WCTD-WJW & MI-Ph. & MI-S. & MI-Chl. $a(\mathrm{PYK})$ & WCTD-PYK \\
\hline $18: 00$ & 1.63 & 1.61 & 1.83 & 1.60 & 2.6 & 1.26 & 1.53 & 1.25 & 1.8 \\
$20: 00$ & 1.25 & 1.71 & 1.54 & 1.27 & 2.2 & 1.11 & 1.87 & 1.39 & 3.5 \\
$22: 00$ & 1.10 & 1.66 & 1.54 & 1.06 & 2.4 & 1.04 & 1.72 & 1.32 & 6.2 \\
$00: 00$ & 1.06 & 1.39 & 1.52 & 0.94 & 2.1 & 1.02 & 1.68 & 1.23 & 4.7 \\
$02: 00$ & 1.04 & 1.35 & 1.50 & 0.93 & 2.4 & 1.04 & 1.95 & 1.25 & 4.5 \\
$04: 00$ & 1.04 & 1.23 & 1.39 & 0.89 & 2.5 & 1.05 & 1.50 & 1.16 & 6.7 \\
$06: 00$ & 1.07 & 1.34 & 1.90 & 0.90 & 2.0 & 1.44 & 1.54 & 1.06 & 4.1 \\
$08: 00$ & 1.10 & 1.35 & 2.00 & 1.22 & 1.8 & 1.94 & 1.55 & 1.13 & 3.7 \\
$10: 00$ & 1.26 & 1.84 & 1.49 & 1.26 & 2.7 & 1.93 & 1.66 & 1.66 & 3.8 \\
$12: 00$ & 1.53 & 1.80 & 1.75 & 1.62 & 2.2 & 1.62 & 1.82 & 1.82 & 2.5 \\
$14: 00$ & 1.23 & 1.60 & 1.93 & 1.06 & 3.0 & 2.00 & 1.97 & 1.97 & 1.7 \\
$16: 00$ & 1.64 & 1.87 & 1.86 & 1.79 & 3.1 & 1.55 & 1.33 & 1.33 & 2.0 \\
\hline
\end{tabular}

*MI-P. ,MI-E. , MI-K. , MI-Chl. a (WJW) ,MI-Ph., MI-S., MI-Chl. a (PYK) 分别代表倪氏拟多甲藻、膝曲裸藻、具尾逗 隐藻、吴家湾叶绿素 $\mathrm{a} 、$ 塔胞藻、汉斯冠盘藻、平邑口叶绿素 $\mathrm{a}$ 的 $M I$ 指数.

2.3 .3 具尾逗隐藻 集中分布在 $5 \mathrm{~m}$ 以上水层, $M I$ 指数在 1.39 到 1.94 之间 (表 1 ), 表明其在 此昼夜周期内呈聚集分布, 最大密度出现在 18: 00 的 $1 \mathrm{~m}$ 水层, 为 $3.55 \times 10^{6} \mathrm{cells} / \mathrm{L}$. 随着光照 的增强,具尾逗隐藻表现出一定的趋光性, 向上 水层聚集; 在 $12: 00-14: 00$, 光强达到最大时, 它由表层向下迁移, 表现出一定的避光性 (图 $4 \mathrm{c}$ ). 虽然在晚间 00:00 至 06:00 的 3m 水层内， 具尾逗隐藻的密度略低于白天水层中的密度,但 $\mathrm{K}-\mathrm{S}$ 检验表明此时段与白天的垂直分布类型没 有显著差异 $(P>0.05)$.

2.3 .4 汉斯冠盘藻 主要分布于 $5 \mathrm{~m}$ 以上水层, 最大密度出现在 06: 00 时的 $1 \mathrm{~m}$ 水层, 为 $4.15 \times$ $10^{8}$ cells $/$ L. $M I$ 指数为 $1.33-1.97$ (表 1 ), 表明 其在此昼夜周期内聚集分布. 从 22: 00 到04:00, $1 \mathrm{~m}$ 以上水层中的密度比白天略低 (图 5a), 但 $\mathrm{K}$ $\mathrm{S}$ 检验表明汉斯冠盘藻夜晚和白天的垂直分布 类型没有显著差异 $(P>0.05)$.

2.3.5 塔胞藻 从 10:00 到 20: 00, 主要分布于 $5 \mathrm{~m}$ 以上水层, 最大密度出现在 10:00 的 $1 \mathrm{~m}$ 水 层, 为 $1.37 \times 10^{7}$ cells $/$ L. 22:00 到 04:00, 水柱中 的密度小于白天, 06: 00 日出后到 $08: 00,2 \mathrm{~m}$ 以 上水层中细胞密度比夜间明显增高 (图 $5 \mathrm{~b}$ ). 塔 胞藻白天在水柱中趋于集群分布, $M I$ 值为 $1.27-$ $2.00 ; 22: 00$ 后趋于随机分布, $M I$ 指数约等于 1 (表 1). K-S 检验表明,塔胞藻白天与晚间在水 柱中的垂直分布类型有显著差异 $(P<0.05)$, 具 有昼夜垂直迁移现象.

\section{4 浮游植物昼夜分布格局的影响因素}

Sperman 相关分析表明 (表 2)，对于倪氏拟

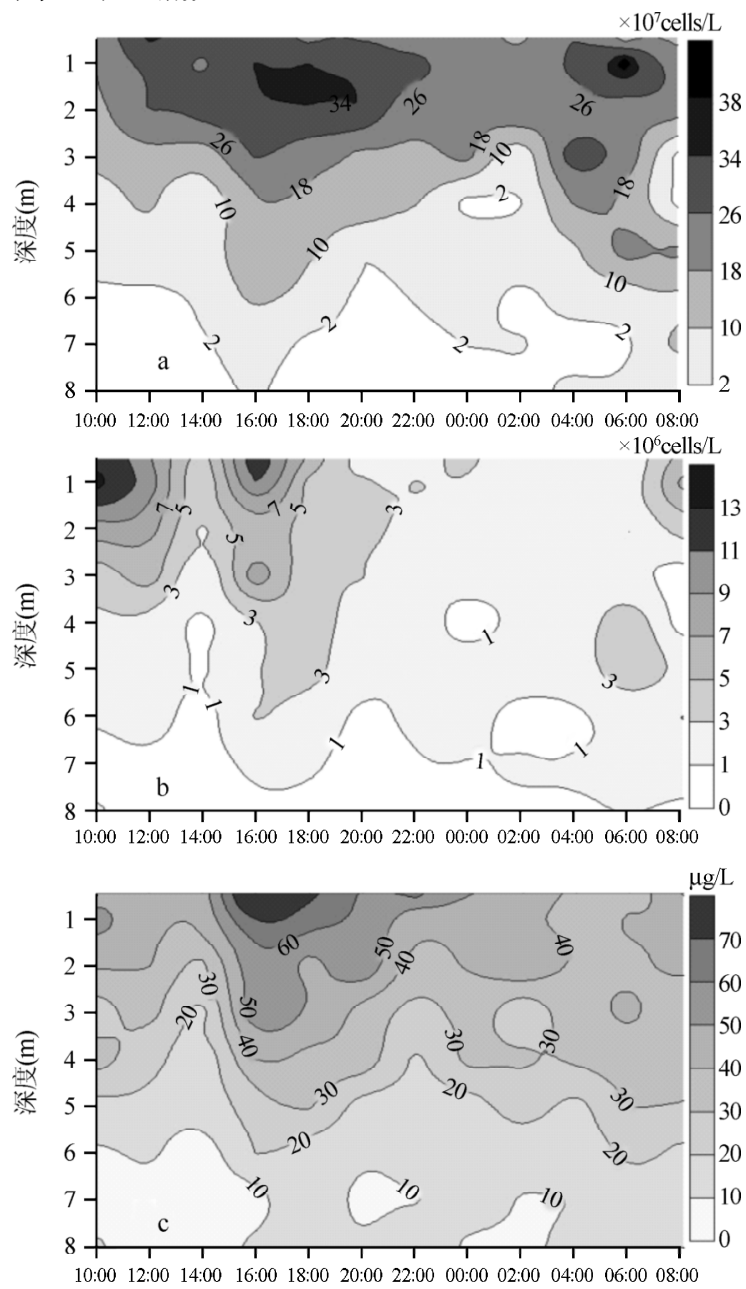

图 5 PYK 汉斯冠盘藻 (a), 塔胞藻 (b) 和 Chl. a(c) 时间一深度等值图

Fig. 5 Depth-time diagram of Stephanodiscus hantzschii( a), Phramidomonas sp. (b) and Chl. a(c) in PYK 
表 2 优势浮游植物 $M I$ 指数与环境变量的相关系数

Tab. 2 Correlation coefficients between environmental variable and $M I$ of dominant phytoplankton

\begin{tabular}{ccc}
\hline$M I$ & $L A\left(Z_{\text {eu }}: Z_{\text {mix }}\right)$ & WCTD \\
\hline$M I-P .(n=12)$ & $0.759^{* *}$ & 0.463 \\
$M I-E .(n=12)$ & 0.537 & 0.469 \\
$M I-K .(n=12)$ & 0.574 & 0.158 \\
$M I-P h . \quad(n=12)$ & $0.849^{* *}$ & 0.007 \\
$M I-S .(n=12)$ & 0.287 & -0.112 \\
\hline
\end{tabular}

$* *$ 表示在 0.01 水平检验显著.
多甲藻和塔胞藻, $M I$ 均与光照强度极显著正相关 $(P<0.01)$, 线性方程分别为: 倪氏拟多甲藻: $M I=$ $1.052+0.046 L A\left(R^{2}=0.576, P=0.008, n=12\right)$; 塔 胞藻: $M I=1.089+0.999 L A\left(R^{2}=0.720, P<0.001\right.$, $n=12)$, 分别解释了昼夜变化的 $57.6 \%$ 和 $72.0 \%$, 说明光照强度的变化是改变其昼夜垂直分布格局的 首要环境因子. 而其他藻类的昼夜垂直分布格局与 光照强度的变化无显著相关 $(P>0.05)$. 水柱温差虽 然有一定的波动, 但最大温度梯度没有超过 $1^{\circ} \mathrm{C} / \mathrm{m}$, 所以没有温跃层出现, 与浮游植物的昼夜垂直分布 格局变化没有显著的相关关系 $(P>0.05$, 表 2$)$.

\section{3 讨论}

鞭毛藻类能够自由游动, 属于主动迁移类型, 它们能够根据自身所需营养和光照的需要而自主调整在 水体中的位置. 在香溪河库湾春季水华中, 优势浮游植物多为鞭毛藻类, 但它们的昼夜垂直分布和迁移行为 不同.

倪氏拟多甲藻主要分布于 $4 \mathrm{~m}$ 以上水层, 具有明显的昼夜垂直迁移现象,白天主要聚集分布于水体近表 层, 晚间在水柱中趋于均匀分布, 与 $\mathrm{Xu}$ 等 $^{[19]}$ 的研究结果相同. 昼夜垂直迁移是在甲藻中普遍存在的现 象 ${ }^{[9]}$. 采样期间水体无分层现象, 没有温跃层出现, 各水层的硝氮和磷酸盐浓度已足以满足其生长的需要; 相关分析表明, 光照是倪氏拟多甲藻昼夜垂直迁移的主导因素. Clegg 等 ${ }^{\left[{ }^{[0]}\right.}$ 的实验结果表明, 假设光照是影 响藻类分布的唯一因素, 且水流运动不足以阻止这些游泳速度在 $40-100 \mu \mathrm{m} / \mathrm{s}$ 的鞭毛藻类时, 甲藻细胞分 布于水柱的近表层, 而裸藻则在真光层的最底部, 这一点在我们的实验中也得到了证实.

膝曲裸藻在整个水柱内几乎均匀分布, 没有明显的昼夜垂直迁移现象, 在正午前后表现出一定的趋光 性. Yoshimasa 等 $^{[31]}$ 在对日本一个浅水湖泊的浮游植物的昼夜垂直分布研究时发现, 当水体分层消失时,裸 藻在整个水柱中均匀分布, 这与我们对膝曲裸藻的研究结果是相同的. 文献报道裸藻能够生活在光照强度 很低的水层 ${ }^{[7]}$. 随着昼夜周期内光照强度的改变, 膝曲裸藻在水柱中的垂直分布格局并没有明显改变, 水下 光照强度的差异对它垂直分布的影响较小, 水体的轻微扰动以及趋光性使得它在表层下较浅水体中聚集.

具尾逗隐藻没有明显的昼夜垂直迁移活动, 与 George 和 Heaney ${ }^{[8]}$ 报道的卵形隐藻 (Cryptomonas ovata) 的昼夜垂直迁移类型相同. 12:00 到 14:00 光照强度较高时, 具尾逗隐藻在表层向下较浅水体中的密度较 高, 避免光抑制的产生, Frempong ${ }^{[32]}$ 对卵形隐藻的研究中也发现了这一现象. Knapp 等 ${ }^{[3]}$ 发现美国 Cross 水 库中的隐藻 (Cryptomonas spp. ) 只有当光照强度和水层中的光照梯度达到一定值时才会发生垂直迁移, 二者 缺一不可, 有可能因为水层光照梯度还没有达到具尾逗隐藻所需要求, 加上水体轻微扰动作用, 才会出现本 文所观察到的昼夜垂直分布格局.

营养盐也被认为是影响鞭毛藻类垂直迁移的因素, 实验研究表明, 当营养充足时, 鞭毛藻类有更强的趋 光性, 而在表层水体营养缺乏时, 鞭毛藻才会在夜间吸收底层水的营养 ${ }^{[33]}$. 香溪河库湾氮磷浓度已远远超出 国际公认的水体富营养化國值 (图 3), 因此, 营养可能不是限制香溪河鞭毛藻类昼夜垂直迁移的环境因子.

汉斯冠盘藻主要聚集分布于 $4 \mathrm{~m}$ 以上水层, 其昼夜垂直分布类型没有显著差异. 硅藻属于不能自由运动 的被动迁移类型, 需要依靠水体的混合而悬浮于水柱中, 它们具有较高的沉降比, 最大叶绿素 $\mathrm{a}$ 常出现在较 深水层 ${ }^{[34]}$. 与此不同的是, 汉斯冠盘藻在水柱近表层细胞密度最大, 这可能是由于汉斯冠盘澡个体微小 (直 径仅为 3-5 $\mu \mathrm{m})$, 被转运到真光层后, 可以在某一水层中保持较长时间 ${ }^{[35-36]}$, 又因其具有较小的表面积一体 积比, 繁殖速度较快, 易于取得竞争优势. 不能运动的藻类在水柱中垂直分布的改变易受由风等引起的水体 扰动的影响 ${ }^{[31]}$, 也有文献报道硅藻的昼夜垂直分布与混合层深度的昼夜变化有关 ${ }^{[37]}$.

综上所述, 香溪河库湾春季水华期间优势浮游植物具有不同的昼夜垂直分布类型, 浮游植物的昼夜垂 直分布和迁移类型是藻类本身内在的生理节律和外界光照、水体扰动因素等共同作用的结果 ${ }^{[6,31]}$. 倪氏拟多 
甲藻和塔胞藻具有昼夜垂直迁移现象, 光照强度的变化是影响其昼夜垂直迁移行为的重要因素. 膝曲裸藻 和具尾逗隐藻具有趋光性, 它们的昼夜分布格局受光照的昼夜变化及水体扰动的共同影响. 汉斯冠盘藻不 能自由游动, 它的昼夜分布格局可能主要受水体扰动的影响. 另外, 鞭毛藻类在春季大量发生, 随着光照强 度的变化表现出一定的趋光性或避光性,并非表层水体密度最高. 因此,进行水华监测和治理时,在关注表 层水华的同时,对“水内水华”应引起足够的重视.

\section{4 参考文献}

[ 1 ] Hsiao SIC. Diel, tidal and vertical variations of phytoplankton and its environment in Frobisher Bay. Arctic, 1992,45(4) : 327-337.

[ 2 ] Sommer U, Gliwicz ZM. Long range vertical migration of Volvox in tropical lake Cahora Bassa (Mozambique). Limnology and Oceanography, 1986,31(3):650-653.

[ 3 ] Knapp CW, De Jr FN, Graham DW et al. Physical and chemical conditions surrounding the diurnal vertical migration of Cryptomonas spp. (Cryptophyceae) in a seasonally stratified midwestern reservoir (USA). Journal of Phycology, 2003, $39: 855-861$.

[ 4 ] Townsend DW, Bennett SL, Thomas MA. Diel vertical distributions of the red tide dinoflagellate Alexandrium fundyense in the Gulf of Maine. Deep-Sea Research II , 2005, 52(19-21):2593-2602.

[ 5 ] Hajdu S, Höglander H, Larsson U. Phytoplankton vertical distribution and composition in Baltic Sea cyanobacterial blooms. Harmful Algae, 2007, 6:189-205.

[ 6 ] Olli K. Diel vertical migration of phytoplankton and heterotrophic flagellates in the Gulf of Riga. Journal of Marine System, $1999, \mathbf{2 3}(1-3): 145-163$.

[ 7 ] Nygaard G. Vertical and seasonal distribution of some motile freshwater plankton algae in relation to some environemental factors. Archiv fiur Hydrobiologie Supplement, 1977, 51 :67-76.

[ 8 ] George DG, Heaney SI. Factors influencing the spatial distribution of phytoplankton in a small productive lake. Journal of Ecology, 1978, $66: 133-155$.

[ 9 ] Olli K, Heisanen A, Kohikari K. Vertical migration of autotrophic micro-organisms during a vernal bloom at the coastal Baltic Sea-coexistence through niche separation. Hydrobiology, 1998, 363:179-189.

[10] Reichwaldt ES, Stinbor H. The impact of diel vertical migration of Daphnia on phytoplankton dynamics. Oecologia, 2005, $146: 50-56$.

[11] Becker V, Huszar VLM, Crossetti LO. Responses of phytoplankton functional groups to the mixing regime in a deep subtropical reservoir. Hydrobiologia, 2009, 628(1) :137-151.

[12] Ptacnik R, Diehl S, Berger S. Performance of sinking and nonsinking phytoplankton taxa in a gradient of mixing depths. Limnology and Oceanography, 2003, 48:1903-1912.

[13 ] Becker V, de Souza Cardoso L, Huszar VLM. Diel variation of phytoplankton functional groups in a subtropical reservoir in southern Brazil during an autumnal stratification period. Aquatic Ecology, 2009, 43 :285-293.

[14] Rangel LM, Silva LHS, Arcifa MS et al. Driving forces of the diet distribution of phytoplankton functional groups in a shallow tropical lake (Lake Monte Alegre, Southeast Brazil). Brazilian Journal of Biology, 2009, 69(1) : 75-85.

[15] 周广杰,况琪军,刘国祥等. 三峡库区藻类水华调查及毒理学研究. 水生生物学报,2006,30(1):37-41.

[16] Ye L, Han XQ, Xu YY et al. Spatial analysis for spring bloom and nutrient limitation in Xiangxi Bay of Three-Gorges Reservoir. Environmental Monitoring and Assessment, 2007,127:135-145.

[17] Zeng H, Song LR, Yu ZG et al. Distribution of phytoplankton in the Three-Gorge Reservoir during rainy and dry seasons. Science of the Total Environment, 2006, 367 (2-3):999-1009.

[18] 徐耀阳, 蔡庆华, 黎道丰等. 三峡水库香溪河库湾拟多甲藻昼夜垂直分布初步研究. 武汉植物学研究, 2008, 26 (6) :608-612.

[19] Xu YY, Cai QH, Wang L et al. Diel vertical migration of Peridinopsis niei, Liu et al., a new species of dinoflagellates in an eutrophic bay of Three-Gorge Reservoir, China. Aquatic Ecology, 2009,44(2) :387-395

[20] 杨正健,刘德富,易仲强等. 三峡水库香溪河库湾拟多甲藻的昼夜垂直迁移特性. 环境科学研究, 2010,23(1): 26-32. 
[21] 章宗涉,黄祥飞.淡水浮游生物研究方法. 北京:科学出版社,1991.

[22］国家环境保护总局. 水和废水监测分析方法. 北京:中国环境科学出版社,2002.

[23] Thackeray SJ, George DG, Jones RI et al. Statistical quantification of the effect of thermal stratification on patterns of dispersion in a freshwater zooplankton community. Aquatic Ecology, 2006, 40:23-32.

[24] Hills JM, Thomason JC. Multi-scale analysis of settlement density and pattern dynamics of the barnacle Semibalanus balanoides. Marine Ecology Progress Series, 1996, 138:103-115.

[25] Quinn VS, Graves BM. Space use in response to conspecifics by the red-backed salamander ( Plethodon cinereus, Plethodontidae, Caudata). Ethology, 1999, 105 :993-1002.

[26] Smith W, Beet A, Solow AR. Testing for shifts in the vertical distribution of plankton using a robust kolmogorov-smirnov like statistic. Journal of Agricultural, Biological, and Environmental Statistics, 1998, 3(4) :421-429.

[27] Solow AR, Bollens SM, Beet A. Comparing two vertical plankton distributions. Limnology and Oceanography, 2000,45 (2) :506-509.

[28 ] Kunz TJ, Diehl S. Phytoplankton, light and nutrients along gradient of mixing depth: A field test of producer-resource theory. Freshwater Biology, 2003, 48:1050-1063.

[29] Jensen P, Jeppesen E, Olrik K et al. Impact of nutrients and physical factors on the shift from cyanobacterial to chlorophyte dominance in shallow Dianchi lakes. Canadian Journal of Fisheries and Aquatic Sciences, 1994, 51:1692-1699.

[30 ] Clegg MR, Maberly SC, Jones RI. The effect of photon irradiance on the behavioral ecology and potential niche separation of freshwater phytoplanktonic flagellates. Journal of Phycology, 2003, 39:650-662.

[31] Yoshimasa Y, Nakahara H. Seasonal variation in the diel vertical distribution of phytoplankton and zooplankton in a shallow pond. Phycological Research, 2006, 54:280-293.

[32] Frempong E. Diel variation in the abundance, vertical distribution, and species composition of phytoplankton in a eutrophic English lake. Journal of Ecology, 1981, 69(3) :919-939.

[33] Olsson P, Graneli E. Observations on diurnal vertical migration and phased cell division for threecoexisting marine dinoflagellates. Journal of Plankton Research, 1991, 13:1313-1324.

[34] Barbiero RP, McNair CM. The dynamic of vertical chlorophyll distribution in an oligomesotrophic lake. Journal of Plankton Research, 1996, 18:225-237.

[35] Tang EPY. The allometry of algal growth rates. Journal of Plankton Research, 1995, 17 :1325-1335.

[36] Kagami M, Urabe J. Phytoplankton growth rate as a function of cell size: an experimental test in Lake Biwa. Limnology, 2001, 2 :111-117.

[37] Vidal J, Moreno-Ostos E, Escot C et al. The effects of diel changes in circulation and mixing on the longitudinal distribution of phytoplankton in a cyao-shaped Mediterranean reservoir. Freshwater Biology, 2010, 55 : 1945-1957. 